\title{
Utilisation of kidneys from deceased donors at increased risk of infectious disease transmission: a step in the right direction
}

\author{
Chris J. Callaghan ${ }^{1}$ (D) $\cdot$ Stephen D. Marks ${ }^{2,3}$ (D)
}

Received: 24 June 2019 / Accepted: 24 July 2019 / Published online: 30 October 2019

(C) IPNA 2019

\section{Introduction}

Renal transplantation is acknowledged as the gold standard therapy for children with end-stage kidney disease (ESKD), resulting in improved survival, better growth, and more favourable social outcomes when compared with remaining on dialysis [1,2]. A kidney from a living donor is the best option for these children due to a shorter waiting time and better short- and long-term graft function and survival than receiving a kidney from a deceased donor [3, 4]. However, prioritising children for deceased donor renal transplantation resulting in shorter waiting times is leading to some centres reducing their living donor rates [5]. A degree of uncertainty is another drawback to deceased donor kidney transplantation; a history cannot be taken from a deceased patient and few of us tell our loved ones every detail of our medical history or social behaviours. This is especially relevant when we attempt to quantify the risk of transmission of serious blood-borne viruses (BBV), such as human immunodeficiency virus (HIV), hepatitis B virus (HBV) and hepatitis $\mathrm{C}$ virus (HCV), from a deceased donor.

\section{Donors with increased risk for disease transmission}

Hwang et al. report on the experience of transplanting kidneys from deceased donors at increased risk of BBV disease

Chris J. Callaghan

chris.callaghan@gstt.nhs.uk

1 Department of Nephrology and Transplantation, Guy's and St Thomas' NHS Foundation Trust, London SE1 9RT, UK

2 Department of Paediatric Nephrology, Great Ormond Street Hospital for Children NHS Foundation Trust, Great Ormond Street, London WC1N 3JH, UK

3 University College London Great Ormond Street Institute of Child Health, NIHR Great Ormond Street Hospital Biomedical Research Centre, London WC1N 1EH, UK transmission into paediatric recipients in the United States of America (USA) [6]. These donor risk factors include sexual practices associated with increased risk, illicit use of injectable drugs, and incarceration. Such donors in the USA are designated as being of increased risk for disease transmission (IRD), with specific focus on risk factors for HIV, HBV and HCV. This national study from 2004 to 2017 demonstrated excellent patient and renal allograft outcomes in 473 children who received kidney-only transplants from IRD donors with no apparent cases of viral transmission of HIV, HBV or HCV. The authors calculated that improved utilisation of IRD donors could significantly increase paediatric kidney transplant rates in the USA. However, transplant clinicians need to carefully consider whether they should accept these organs from IRD donors and if this should become their normal practice in 2019. For those who are less risk averse, transplant clinicians should consider what information should be given to the proposed paediatric recipient and family at the time of listing for deceased donor renal transplantation as well as at the time of organ donor offer with IRD. Transplant clinicians should be aware of their updated local facilities for testing in prospective paediatric recipients and what treatments are available to those paediatric recipients who develop BBV after transplantation of organs from donors with IRD.

This study will provide encouragement to paediatric transplant teams considering implanting kidneys from deceased donors without serological evidence of BBV infection but with increased risk behaviours. However, this is a complex field, and transplant clinicians must be aware of other important issues discussed in this manuscript.

\section{Differences in IRD donors and transmission risks}

It is unclear how generalisable these findings are outside of the USA as IRD donors make up a relatively large (and increasing) proportion of the deceased donor population in the USA [7], at 
least partly due to an epidemic of opioid use [8]. Deceased donors with a history of drug overdose are far more common in the USA than Australia and New Zealand or the UK with rates of $9.3 \%$ versus $2.7 \%$ and $0.3 \%$, respectively [9].

In addition, when comparing utilisation rates of IRD donors, it is imperative to consider what the underlying prevalence of BBV in the population. Estimated prevalence of HIV in intravenous drug user (IVDU) populations are $3.6 \%, 1.7 \%$, $1.3 \%$ and $0.2 \%$ in the USA, New Zealand, Australia and the UK, respectively. Estimated prevalence data of HCV in IVDU populations are $73 \%, 57 \%, 57 \%$ and $50 \%$ in the USA, New Zealand, Australia and the UK, respectively [9].

\section{Nucleic acid testing}

Given the relatively common frequency of IVDU donors in the USA, it is understandable that nucleic acid testing (NAT) for HIV, HBV and HCV is mandatory for those deceased donors identified as IRD. NAT tests, which detect viral DNA or RNA, significantly shorten the 'window period', which is the duration between exposure to an infectious agent and detection in the infected individual's blood, when compared with serology. Window periods for HIV and HCV are approximately 5 to 9 days for NAT tests, but 1 to 2 months for antibodybased serological tests $[10,11]$. We assume that the IRD donors in Hwang's analysis were both NAT negative and serologically negative. However, NAT tests are not available prior to organ offering in every country.

The availability of NAT testing, the relatively high prevalence of IVDU and recent concerns about the access of children with ESKD to deceased donor kidneys in the USA [12] combine to make the use of IRD donors a more feasible option to patients, families and clinicians. Declining a kidney from an IRD donor prolongs median waiting time by 9.6 months (11.2 months among those under 6 years of age and 8.8 months among those on dialysis) [13]. These drivers may not be present in other countries, specifically, those countries with short waiting times for deceased donor kidney transplantation in Europe [14].

\section{Risk according to exposure timing}

There may be some degree of selection bias evident in this study. The timing of exposure to an infectious agent is important in deciding whether to accept or decline the offer of a kidney from an IRD donor. The risks of disease transmission from a NAT-negative donor with a history of IVDU found in respiratory arrest with a needle in their arm will be significantly higher than the risks associated with a NAT-negative donor who was in prison 11 months ago, although both will be classified as IRD donors $[10,11]$. There are no detailed data on donor risk behaviours leading to IRD classification in this manuscript, although the proportion of donors with IVDU or anoxic brain injury was higher in the IRD group than the nonIRD group [6]. This makes it difficult to accurately characterise the residual risk of viral transmission in this donor group that is likely to be heterogeneous with respect to risk behaviour; this is especially relevant given that the national criteria for identification of IRD donors changed during the study period.

\section{Educational tools}

It is essential that transplant centres that accept organs from IRD donors carefully consider the best way to educate and consent the children and their families on their waiting list. The possibility of accepting an IRD donor for a prospective paediatric recipient should be discussed around the time of listing for transplantation, rather than first raising the issue around the time of organ acceptance. Patients and their families should receive careful education and counselling on the risks and benefits of implanting organs from IRD and nonIRD donors. Specific education packages and outcome prediction tools are available, but are aimed at adults, and are based on practices and data from the USA $[15,16]$. Education packages should not be seen as a 'one off'; patients should be regularly assessed as to their suitability for kidneys from IRD donors, especially those children at increased risk of poor outcomes on the waiting list (such as those running out of dialysis access, highly sensitised paediatric patients and those with rare HLA types or homozygosity).

\section{Post-transplantation monitoring and treatment}

Transplant clinicians must be aware that prospective paediatric recipients of kidneys from IRD donors should be tested post-transplant in order to detect disease transmission. Current guidance in the USA recommends HIV NAT or HIV antigen/ antibody combination assay, HCV NAT, and HBV NAT and hepatitis B surface antigen (HBsAg) testing at 1 to 3 months post-transplant, with anti-hepatitis B surface antibody, antihepatitis B core antibody and either HBV NAT or HBsAg at 12 months post-transplant [17]. NAT testing is required as serological tests are unreliable in the early post-transplant period due to immunosuppression. We suggest that patients and their families be informed of the need for post-transplant investigations to detect disease transmission if transplantation of organs from IRD donors is considered. Transplant units should liaise closely with infectious diseases colleagues to ensure that their approaches to post-transplant testing are valid, and to facilitate early treatment of cases of disease 
transmission, if they occur. Recent reports of successful eradication of $\mathrm{HCV}$ from recipients of known HCV-positive donors are encouraging $[18,19]$.

\section{Conclusion}

These data are reassuring, and the risks of BBV transmission from this donor group seem low. However, the use of kidneys from IRD donors still requires careful consideration of donor, waiting list and recipient factors. Centres must ensure that patient and family education and consent processes are appropriate, and that donor and recipient testing policies are robust. With these caveats in mind, we hope that this manuscript will stimulate the increased use of kidneys from IRD deceased donors, leading to reduced waiting times and improved outcomes for children with ESKD where there are no living donor options.

Acknowledgements This project was supported by the National Institute for Health Research (NIHR) Biomedical Research Centers based at Guy's and St Thomas' National Health Service (NHS) Foundation Trust and King's College London as well as Great Ormond Street Hospital for Children NHS Foundation Trust and University College London. The views expressed are those of the authors and not necessarily those of the NHS, the NIHR or the Department of Health.

\section{Compliance with ethical standards}

Conflict of interest The authors declare that they have no conflict of interest.

\section{References}

1. Hart A, Smith JM, Skeans MA, Gustafson SK, Wilk AR, Robinson A, Wainwright JL, Haynes CR, Snyder JJ, Kasiske BL, Israni AK (2018) OPTN/SRTR 2016 Annual Data Report: Kidney. Am J Transplant Suppl 1:18-113

2. Sigurjonsdottir VK, Grimm PC (2019) Living or deceased donor kidney transplantation in children. Curr Opin Pediatr 31(2):232-236

3. Smith JM, Martz K, Blydt-Hansen TD (2013) Pediatric kidney transplant practice patterns and outcome benchmarks, 1987-2010: a report of the North American Pediatric Renal Trials and Collaborative Studies. Pediatr Transplant 17(2):147-157

4. Mumford L, Maxwell H, Ahmad N, Marks SD, Tizard J (2019); in press) The impact of changing practice on improved outcomes of paediatric renal transplantation in the United Kingdom: a 25 years review. Transpl Int. https://doi.org/10.1111/tri.13418

5. Smith JM, Brewer ED (2017) Decreasing living donor rates in pediatric kidney transplantation: a time for action. Pediatr Transplant 21(2). https://doi.org/10.1111/petr.12883

6. Hwang CS, Gattineni J, MacConmara M (2019) Utilizing increased risk for disease (IRD) transmission kidneys for pediatric renal transplant recipients. Pediatr Nephrol in press

7. Kucirka LM, Bowring MG, Massie AB, Luo X, Nicholas LH, Segev DL (2015) Landscape of deceased donors labeled increased risk for disease transmission under new guidelines. Am J Transplant 15(12):3215-3223
8. Durand CM, Bowring MG, Thomas AG, Kucirka LM, Massie AB, Cameron A, Desai NM, Sulkowski M, Segev DL (2018) The drug overdose epidemic and deceased-donor transplantation in the United States: a national registry study. Ann Intern Med 168(10): 702-711

9. White SL, Rawlinson W, Boan P, Sheppeard V, Wong G, Waller K, Opdam H, Kaldor J, Fink M, Verran D, Webster A, Wyburn K, Grayson L, Glanville A, Cross N, Irish A, Coates T, Griffin A, Snell G, Alexander SI, Campbell S, Chadban S, Macdonald P, Manley P, Mehakovic E, Ramachandran V, Mitchell A, Ison M (2018) Infectious disease transmission in solid organ transplantation: donor evaluation, recipient risk, and outcomes of transmission. Transplant Direct 5(1):e416. https://doi.org/10.1097/TXD. 0000000000000852

10. Kucirka LM, Sarathy H, Govindan P, Wolf JH, Elllison TA, Hart LJ, Montgomery RA, Ros RL, Segev DL (2011) Risk of window period HIV infection in high infectious risk donors: systematic review and meta-analysis. Am J Transplant 11(16):1176-1187

11. Kucirka LM, Sarathy H, Govindan P, Wolf JH, Elllison TA, Hart LJ, Montgomery RA, Ros RL, Segev DL (2011) Risk of window period hepatitis-C infection in high infectious risk donors: systematic review and meta-analysis. Am J Transplant 11(16):1188-1200

12. Jackson KR, Zhou S, Ruck J, Massie AB, Holscher C, Kernodle A, Glorioso J, Motter J, Neu A, Desai N, Segev DL, Garonizik-Wang J (2019); in press) Pediatric deceased donor kidney transplant outcomes under the kidney allocation scheme. Am J Transplant. https://doi.org/10.1111/ajt/15419

13. Bowring MG, Jackson KR, Wasik H, Neu A, Garonizik-Wang J, Durand C, Desai N, Massie AB, Segev DL (2019); in press) Outcomes after declining increased infectious risk kidney offers for pediatric candidates in the United States. Transplantation. https://doi.org/10.1097/TP.0000000000002674

14. Harambat J, van Stralen KJ, Schaefer F, Grenda R, Jankauskiene A, Kostic M, Macher MA, Maxwell H, Puretic Z, Raes A, Rubik J, Sórensen SS, Toots U, Topaloglu R, Tönshoff B, Verrina E, Jager KJ (2013) Disparities in policies, practices and rates of pediatric kidney transplantation in Europe. Am J Transplant 13(8):2066-2074

15. Gordon EJ, Sohn MW, Chang CH, McNatt G, Vera K, Beauvais N, Warren E, Mannon RB, Ison MG (2017) Effect of a mobile Web App on kidney transplant candidates' knowledge about increased risk donor kidneys: a randomised controlled trial. Transplantation 101(6):1167-1176

16. Johns Hopkins IRD Kidney Transplant Calculator. http://www. transplantmodels.com/ird. Accessed 23 June 2019

17. Deem SL, Lee I, Unscheid CA, Kuehnert MJ, United States Public Health Service (2013) PHS guideline for reducing human immunodeficiency virus, hepatitis B virus, and hepatitis C virus transmission through organ transplantation. Public Health Rep 128(4):247343

18. Reese PP, Abt PL, Blumberg EA, Van Deerlin VM, Bloom RD, Potluri VS, Levine M, Porrett P, Sawinski D, Nazarian SM, Naji A, Hasz R, Suplee L, Trofe-Clark J, Sicilia A, McCauley M, Gentile C, Smith J, Niknam BA, Bleicher M, Reddy KR, Goldberg DS (2018) Twelve-month outcomes after transplant of hepatitis C-infected kidneys into uninfected recipients: a single-group trial. Ann Intern Med 169(5):273-281

19. Goldberg DS, Abt PL, Blumberg EA, Van Deerlin VM, Levine M, Reddy KR, Bloom RD, Nazarian SM, Sawinski D, Porrett P, Naji A, Hasz R, Suplee L, Trofe-Clark J, Sicilia A, McCauley M, Farooqi M, Gentile C, Smith J, Reese PP (2017) Trial of transplantation of HCV-infected kidneys into uninfected recipients. N Engl J Med 376(24):2394-2395

Publisher's note Springer Nature remains neutral with regard to jurisdictional claims in published maps and institutional affiliations. 